\title{
Passive and active constant force-displacement characteristics and optimization of a long-stroke linear actuator
}

\section{Citation for published version (APA):}

Encica, L., Paulides, J. J. H., \& Lomonova, E. A. (2008). Passive and active constant force-displacement characteristics and optimization of a long-stroke linear actuator. In 11th International Conference on Optimization of Electrical and Electronic Equipment, 2008 : OPTIM 2008 ; Bra, sov, Romania, 22 - 24 May 2008 (pp. 117124). Institute of Electrical and Electronics Engineers. https://doi.org/10.1109/OPTIM.2008.4602397

DOI:

10.1109/OPTIM.2008.4602397

Document status and date:

Published: 01/01/2008

\section{Document Version:}

Publisher's PDF, also known as Version of Record (includes final page, issue and volume numbers)

\section{Please check the document version of this publication:}

- A submitted manuscript is the version of the article upon submission and before peer-review. There can be important differences between the submitted version and the official published version of record. People interested in the research are advised to contact the author for the final version of the publication, or visit the DOI to the publisher's website.

- The final author version and the galley proof are versions of the publication after peer review.

- The final published version features the final layout of the paper including the volume, issue and page numbers.

Link to publication

\footnotetext{
General rights

- You may freely distribute the URL identifying the publication in the public portal. follow below link for the End User Agreement:

www.tue.nl/taverne

\section{Take down policy}

If you believe that this document breaches copyright please contact us at:

openaccess@tue.nl

providing details and we will investigate your claim.
}

Copyright and moral rights for the publications made accessible in the public portal are retained by the authors and/or other copyright owners and it is a condition of accessing publications that users recognise and abide by the legal requirements associated with these rights.

- Users may download and print one copy of any publication from the public portal for the purpose of private study or research.

- You may not further distribute the material or use it for any profit-making activity or commercial gain

If the publication is distributed under the terms of Article $25 \mathrm{fa}$ of the Dutch Copyright Act, indicated by the "Taverne" license above, please 


\title{
Passive and Active Constant Force-Displacement Characteristics and Optimization of a Long- Stroke Linear Actuator
}

\author{
Laurentiu Encica, Student Member, IEEE, Johannes J.H. Paulides, Member, IEEE, \\ and Elena A. Lomonova, Senior Member, IEEE \\ Eindhoven University of Technology, Eindhoven, The Netherlands
}

\begin{abstract}
In applications such as vibration isolation, gravity compensation, pick and place machines, etc., the applicability of commercial low force passive devices is limited and hence would benefit from an improved and preferably variable force level. This paper presents and investigates such a long stroke constant-force versus displacement actuator topology, where analytical and equivalent circuit models are detailed and compared with comprehensive three dimensional (3D) finite element analyses. Furthermore, the optimization of such an actuator by means of aggressive output space mapping is considered. This technique employs a combination of a single analytical equation and a 3D finite element model. Specifically, the optimization is applied to obtain a passive and active force level of $200 \mathrm{~N}$ and $300 \mathrm{~N}$, respectively, where the forcedisplacement response is constant over $60 \%$ to $90 \%$ of the total stroke.
\end{abstract}

\section{INTRODUCTION}

$\mathrm{P}$ ASSIVE constant-force actuators (PCFA) are commercially available for low force levels [1]. Measurements performed on such an actuator (Fig. 1) show indeed a constant level of the force output versus translator displacement for a certain stroke range. However, the internal topology of the measured actuator is unknown and thus the actuator topologies discussed in this paper (Figs. 2, 3 and 4) are independently derived.

In applications such as vibration isolation, gravity compensation, pick and place machines, etc. or in applications where the PCFA is placed in parallel to a linear brushless actuator, the applicability of low force passive devices is limited and hence would benefit from

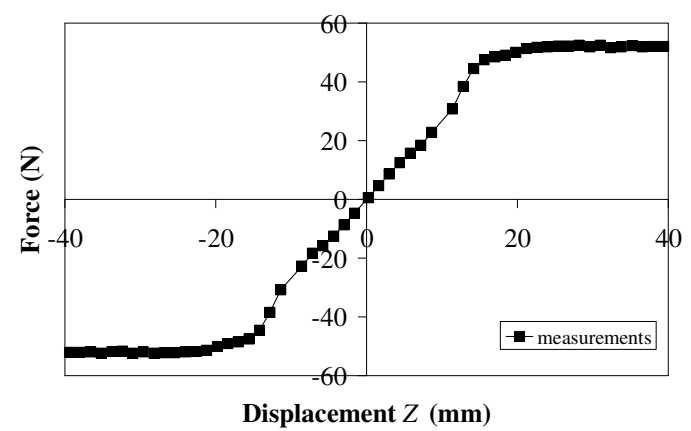

Figure 1. Measurements results for a commercial constant-force actuator.

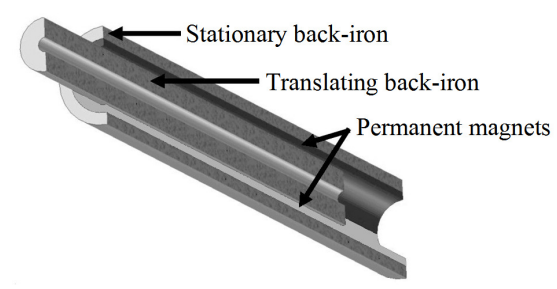

Figure 2. Passive constant-force actuator with low pole number.

an improved and preferably adjustable force level. The constant force characteristic is independent on the displacement of the PCFA translator and therefore excludes the position sensor, which is especially important for high production volume applications where low cost is important. A further enhancement would be achieved if the PCFA's force output could be increased or decreased by means of DC excitation, with the resulting actuator configuration being denoted as an active constant-force actuator (ACFA). For example, in pick and place machines, where the load is constantly varying, the changing gravitational force could be counteracted by an ACFA instead of attaining the increased force from the linear brushless actuator [2]. Another example is given by fluid flow control applications that require a variable valve position with respect to the desired output flow [3]. In these applications solenoids are used, however although that these devices have a very simple structure they require, in order to produce force, a constant current excitation and, furthermore, the force-per-volume ratio is limited for applications with long-stroke valve motions [3]. This paper investigates such a long stroke constant force actuator topology with increased and adjustable force, where the corresponding topologies are shown in Figs. 3 and 4.

For the initial evaluation of the PCFA and ACFA concepts, analytical and lumped parameter models are derived in Sections II to IV. However, in order to verify their solution accuracy, the actuator performance is evaluated by means of the 3D finite element analysis (FEA) in Section V. This initial analysis is based on a set of arbitrary geometrical parameters and in order to maximize the static performance, the optimal design of a long stroke ACFA is considered in Section VI. A recently introduced optimization technique, i.e. the aggressive 


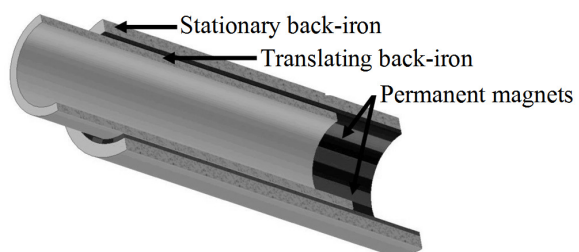

Figure 3. Passive constant-force actuator with high pole number.

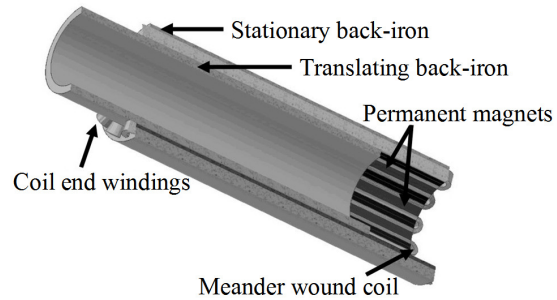

Figure 4. Active constant-force actuator with high pole number (a meander wound coil is placed in between the permanent magnets).

output space-mapping (AOSM), is implemented for this purpose. Finally, the conclusions are given in Section VII.

\section{SIMPLIFIED PASSIVE ANALYTICAL MODEL}

A first estimate of the force capability can be derived from well established analytical expressions. This simplified analytical model is derived based on a number of simplifying assumptions: no leakage fluxes or fringing effects are considered, and the magnet and iron relative permeabilities are taken to be equal to 1 and infinity, respectively. For a magnet material having a linear demagnetization characteristic, with a working point that lies on the linear region, the flux density is given by:

$$
B_{m}=B_{r}+\mu_{o} \mu_{r} H_{m},
$$

where, $B_{m}$ is the working flux density, $H_{m}$ is the corresponding magnetic field strength, $B_{r}$ is the remanent flux density and $\mu_{r}$ is the relative recoil permeability.

Starting from the general form of Ampere's law:

$$
\oint_{C} \bar{H} \cdot d \bar{l}=\iint_{S} \bar{J} \cdot d \bar{A}=I_{e n c},
$$

and considering the magnetic field strength to be (piecewise) constant on the integration path, the simplified expression is obtained:

$$
H_{g} l_{g}+H_{m} l_{m}=0 .
$$

Further, it is assumed that the airgap and magnet flux are equal:

$$
\Phi_{g}=\Phi_{m},
$$

and, therefore, for the surface-mounted magnet rotor topology, which is the only topology considered in this paper, the average magnet flux density, from (1), is:

$$
B_{m}=\frac{B_{r}}{1+\frac{l_{g} S_{m}}{l_{m} S_{g}}},
$$

where $l_{g}$ and $S_{g}$ are the airgap length and surface area, and $l_{m}$ and $S_{m}$ are the magnet thickness and the magnet area, respectively. The airgap flux density can be derived from
(4) as:

$$
B_{g}=B_{m} \frac{S_{m}}{S_{g}}
$$

The force capability of the PCFA is then derived from the rate of change of magnetic co-energy with respect to the translator displacement. The magnetic co-energy over the volume of the problem is given by:

$$
W^{\prime}=\int_{V}\left(\int_{0}^{H} B \cdot d H\right) d V,
$$

and, given the simplifying assumptions, it can be reduced to:

$$
W^{\prime}=\frac{B^{2}}{2 \mu_{0}} S l
$$

The force output, for the direction of travel along the $\mathrm{z}$ axis, is then calculated by:

$$
F_{z}=-\left.\frac{\partial W^{\prime}}{\partial z}\right|_{I=\text { const }},
$$

where, by substituting (5) and (6) in (8), the following expression, which is independent of the $z$-axis displacement due to the exclusion of axial leakage in the analytical model, is obtained for the force amplitude:

$$
F_{z}=-\frac{B_{r}{ }^{2}}{2 \mu_{0}} c_{m} l_{m}\left[\frac{1}{1+\frac{l_{g 1} c_{m}}{l_{m} c_{g 1}}}-\frac{1}{1+\frac{l_{g 2} c_{m}}{l_{m} c_{g 2}}}\right] .
$$

In this, $c_{g}$ and $c_{m}$ are the width of the airgap and magnet flux path, respectively, and the expressions for calculating the various considered parameters are summarized in Table I. In this, $l_{g l}$ and $c_{g l}$ are, respectively, the length and area of the airgap of the overlapping part, $l_{g 2}$ and $c_{g 2}$ are the length and airgap of the non-overlapping part and $l_{m}$ and $c_{m}$ are the length and area of the permanent magnets. The various dimensions of $x_{1}$ to $x_{3}$ and $g$ are shown in Fig. 11 and summarized in Table II. Further, in Table I, $n_{p}$ represents the number of poles, where the use of a low number of poles in PCFAs is common (typically 2-4) as it particularly offers advantages in terms of complexity and cost [1]. Although that, for an increased force level, the choice of pole-pair number is influenced largely by considerations of size and magnetic flux leakage.

The force capability is determined by the specific magnetic loading, i.e. airgap flux density. In surface mounted magnet configurations, scaling-up the magnet thickness can produce considerable increase in airgap flux density, albeit at a diminishing rate of return. The specific force capability could also be adjusted by adding a stator mmf using a meandered wound coil in between the magnets (Fig. 4) which can increase or decrease the amplitude of the constant force characteristic. 
TABLE I

PARAMETER ESTIMATION FOR LPN/HPN CFA/CCFA

\begin{tabular}{ccc}
\hline \hline & LPN & HPN \\
\hline$l_{g 1}$ & $2 \mathrm{~g}$ & $2 \mathrm{~g}$ \\
$c_{g 1}$ & $2 \pi\left(x_{1}+x_{2}+g / 2\right) / n_{p} / 2$ & $2 \pi\left(x_{1}+x_{2}+g / 2\right) / n_{p} / 3$ \\
$l_{g 2}$ & $2 \pi\left(x_{1}+x_{2}+g\right) / n_{p} / 2$ & $2 \pi\left(x_{1}+x_{2}+g\right) / n_{p} \cdot(2 / 3)$ \\
$c_{g 2}$ & $2 \pi\left(x_{1}+x_{2}+g\right) / n_{p} / 2$ & $2 \pi\left(x_{1}+x_{2}+g\right) / n_{p} / 3$ \\
$l_{m}$ & $2 x_{3}$ & $2 x_{3}$ \\
$c_{m}$ & $2 \pi\left(x_{1}+x_{2}+g+x_{3} / 2\right) / n_{p} / 2$ & $2 \pi\left(x_{1}+x_{2}+g+x_{3} / 2\right) / n_{p} / 3$ \\
\hline
\end{tabular}

\section{SIMPLIFIED ACTIVE ANALYTICAL MODEL}

When considering the active device of Fig. 4, the equations of Section II are somewhat changed, where the stator $\mathrm{mmf}$ has to be included, since

$$
H_{g} l_{g}+H_{m} l_{m}=m m f_{c},
$$

and, consequently, the average airgap flux density is given by:

$$
B_{m}=\frac{\mu_{0}}{l_{m}} \frac{m m f_{m}+m m f_{c}}{1+\frac{l_{g} S_{m}}{l_{m} S_{g}}},
$$

where the magnet and stator coil magnetomotive force are respectively $m m f_{m}$ and $m m f_{c}$ (the sign of the $m m f_{c}$ source is negative if its direction opposes the magnet $\mathrm{mmf}$ ). The permanent magnet and stator mmfs are given by:

$$
m m f_{m}=2 \frac{B_{r}}{\mu_{0}} x_{3} \text { and } m m f_{c}=2 I_{c},
$$

respectively. For the ACFA, $I_{c}$ represents the current in the coil and, only for verification purposes, a value of $1300 \mathrm{~A}$ is defined here, which, considering the coil crosssectional geometry calculated with the parameters given in Table II, corresponds to a current density of approximately $12.3 \mathrm{~A} / \mathrm{mm}^{2}$. This current density is characteristic for a well cooled device or ACFA with a reduced duty-cycle. This relative high density is used to illustrate the ACFA force capability in Section V. A reduced current density could also be applied, albeit at a corresponding reduction in force amplitude.

The ACFA force response, assuming infinitely permeable iron and no leakage fluxes, is given by:

$$
\begin{array}{r}
F_{z}=-\frac{\mu_{0}}{2} \frac{c_{m}}{l_{m}}\left(m m f_{m}+m m f_{c}\right)^{2} \cdot \ldots \\
\ldots\left[\frac{1}{1+\frac{l_{g 1} c_{m}}{l_{m} c_{g 1}}}-\frac{1}{1+\frac{l_{g 2} c_{m}}{l_{m} c_{g 2}}}\right],
\end{array}
$$

where the expressions for calculating the various parameters considered for the force calculation of the specific dimensions are summarized in Table I for low pole number (LPN) and high pole number (HPN) PCFA and ACFA topologies.

The analytical expressions (10) and (14) provide fast means to determine the specific force amplitude for passive and active CFAs. However, by not taking into account the aforementioned leakages and flux defocusing, the calculated force response calculations are somewhat different from the force calculated by FEA, and consequently the resulting force response is independent of the Z-displacement. However, by considering the magnetic flux leakage paths this is true only for $80-90 \%$ of the actuator stroke ( $z$-displacement), as will be discussed in Section V. Therefore, the leakage fluxes have to be considered in order to approximate the force response behavior for the entire stroke and, thus, a more comprehensive magnetic equivalent model (MEC) model is considered in the next section.

\section{PASSIVE AND ACTIVE MAGNETIC EQUIVALENT CIRCUIT MODELS}

This magnetic equivalent circuit for the LPN/HPN PCFA (Figs. 2 and 3) is built based on a set of simplifying assumptions: the iron cores are considered linear with a relative magnetic permeability of 1000 , the $2^{\text {nd }}$ quadrant of PM BH-characteristic is considered linear with a remanent flux density of $1.23 \mathrm{~T}$ and its relative recoil permeability is approximated to 1 . The axial crosssection, as shown by Fig. 5, shows the motivation for considering a two part MEC model to estimate the forcedisplacement characteristic. The first part is used for the overlapping part of the actuator, indicated by $R_{l}$ and $R_{2}$ in Fig. 5, and the second part is used to model the nonoverlapping part and the end-leakages, indicated by $R_{6}, R_{5}$ and $R_{10}$ in Fig. 5.

The various reluctance elements of these magnetic equivalent circuit models are calculated starting from the general expression:

$$
R=\frac{l}{\mu_{r} \mu_{0} S},
$$

where a flux tube (flux path) is characterized by the length, $l$, the vacuum and the material relative permeability, $\mu_{0}$ and $\mu_{r}$, and the cross-sectional area, $S$, which may vary with the length. Following the radial $(R$ $\theta$ ) cross-section of the overlapping part of the PCFA, as shown in Fig. 6, the magnetic equivalent circuit from Fig. 6 can be recognized. A more detailed analysis of the MEC method and theory of the magnetic flux tubes can be found in [4] and [5].

In Fig. 7, the PM is modeled as an mmf source in series with a reluctance element, $R_{l}$. The airgap and fringing magnetic flux distribution are modeled by the corresponding reluctance elements, $R_{2}$ and $R_{8}$. The stationary and translating back-iron parts are modeled by the circuit elements, $R_{3}$ and $R_{4}$, respectively. The main magnetic flux path is indicated by $\Phi_{l}$. The flux is determined by using a system of linear equations resulting from Kirchhoff's laws:

$$
\left[A^{(1)}\right] \cdot\left[\Phi^{(1)}\right]=\left[f^{(1)}\right],
$$

where $[A]$ is the coefficient matrix given by: 


$$
\left[A^{(1)}\right]=\left[\begin{array}{ccc}
-1 & -1 & 1 \\
R_{\mathrm{e} 1} & -R_{8} & 0 \\
R_{\mathrm{e} 1} & 0 & R_{4}
\end{array}\right],
$$

and

$$
R_{e 1}=2 R_{1}+2 R_{2}+R_{3} .
$$

The unknown magnetic fluxes are written in the column matrix:

$$
\left[\Phi^{(1)}\right]=\left[\begin{array}{lll}
\Phi_{1} & \Phi_{2} & \Phi_{3}
\end{array}\right]^{T},
$$

and the column vector $\left[f^{(1)}\right]$ is:

$$
\left[f^{(1)}\right]=\left[\begin{array}{lll}
0 & 0 & \operatorname{mmf}_{m}
\end{array}\right] \text {. }
$$

The system is solved for the magnetic fluxes, and the flux densities are calculated with:

$$
B_{i}=\frac{\Phi_{i}}{A_{i}}
$$

The force in $z$-direction is represented by (9), where the co-energy is calculated with:

$$
W^{\prime}=\sum_{k} \frac{B_{k}^{2}}{2 \mu_{0}} S_{k} l_{k} .
$$

The resultant force will have only a $z$-component since the radial component is canceled giving the axial symmetry of the model.

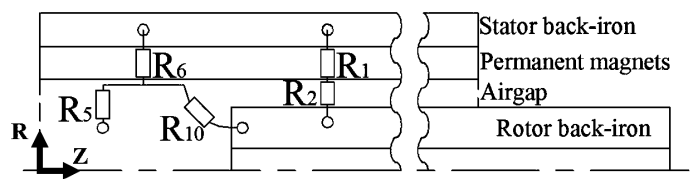

Figure 5. Axial $(R-Z)$ cross-section of CFA indicating the various reluctances used in the MEC models.

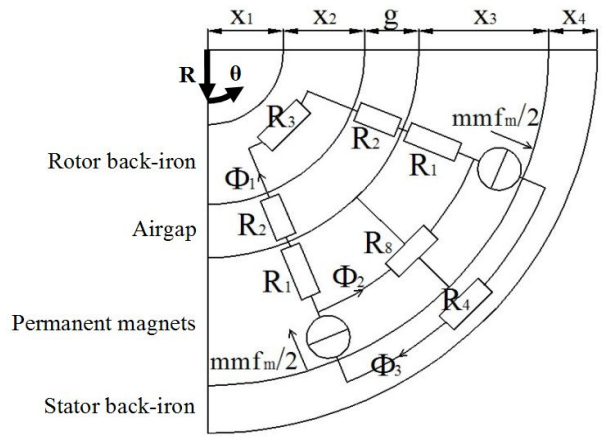

Figure 6. Radial $(R-\theta)$ cross-section of the overlapping PCFA part.

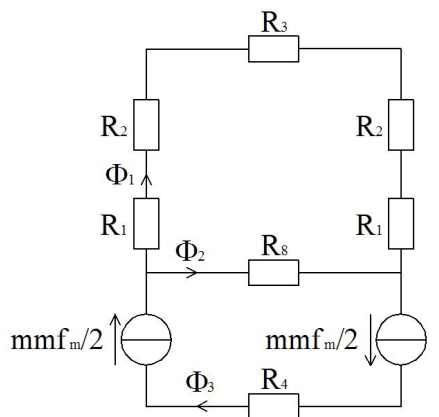

Figure 7. Magnetic equivalent circuit model representation for the overlapping part.

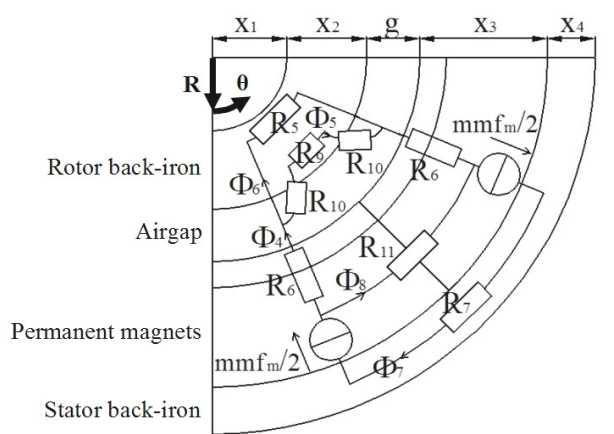

Figure 8. Radial $(R-\theta)$ cross-section of the non-overlapping PCFA part with axial leakage paths as shown in Fig. 4.

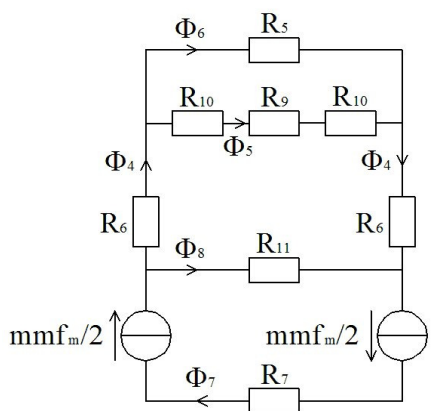

Figure 9. Magnetic equivalent circuit model representation for the non-overlapping part.

In order to include the non-overlapping part and axial end-effect, as shown in Fig. 5, the second MEC model, following the radial $(R-\theta)$ cross-section of Fig. 8, is derived as shown in Fig. 9.The inclusion of the axial leakage introduces a rapidly decreasing change in energy when the translator is moved from its initial position, and thus the nonlinear part of the force response is also captured, as will be shown in Section V.

Using the same analysis as for (16), from Kirchoff's laws follows:

$$
\left[A^{(2)}\right] \cdot\left[\Phi^{(2)}\right]=\left[f^{(2)}\right],
$$

where the coefficient matrix is:

$$
[A]=\left[\begin{array}{ccccc}
1 & -1 & -1 & 0 & 0 \\
1 & 0 & 0 & -1 & 1 \\
2 R_{6} & 0 & R_{5} & R_{7} & 0 \\
2 R_{6} & 0 & R_{5} & 0 & -R_{11} \\
2 R_{6} & R_{e 2} & 0 & R_{7} & 0
\end{array}\right],
$$

for the second MEC model presented in Fig. 9. The reluctance $R_{e 2}$ in this model represents the summation of two times $R_{10}$ and $R_{9}$. The unknown magnetic fluxes are written in the column matrix:

$$
\left[\Phi^{(2)}\right]=\left[\begin{array}{lllll}
\Phi_{4} & \Phi_{5} & \Phi_{6} & \Phi_{7} & \Phi_{8}
\end{array}\right]^{T},
$$

and the column vector $\left[f^{(2)}\right]$ is:

$$
\left[f^{(2)}\right]=\left[\begin{array}{lllll}
0 & 0 & \mathrm{mmf}_{m} & 0 & \mathrm{mmf}_{m}
\end{array}\right]
$$

The derivation of the ACFA's MEC model follows the same pattern, however the reluctance elements representing the stator back-iron and magnets are adjusted to the ACFA topology and the equations (20) and (26) are updated to include the stator mmf: 


$$
\left[f^{(1)}\right]=\left[\begin{array}{lll}
0 & 0 & m m f_{m}+m m f_{c}
\end{array}\right]
$$

for the simplified model of Fig. 7 and:

$$
\begin{array}{r}
{\left[f^{(2)}\right]=\left[\begin{array}{rrr}
0 & 0 & \mathrm{mmf}_{m}+m m f_{c} \ldots \\
& 0 & m m f_{m}+m m f
\end{array}\right]}
\end{array}
$$

for the model of Fig. 9.

In these models all the various reluctances, are determined from (15) and the parameters and dimensions indicated in Tables I and II. The total force is derived using (9), where the total magnetic energy (22) is given by the sum of the energies of both parts of the MEC model. In order to illustrate the respective accuracy of the analytical and the MEC model, they are verified versus finite element models in the next section.

\section{FINITE ELEMENT ANALYSIS AND RESULTS COMPARISON}

The PCFA and ACFA are numerically modeled by means of non-linear 3D FEA software. The electromagnetic force produced on the translator is obtained using the virtual work approach. The 3D magnetostatic solver of the Maxwell 3D (Ansoft Co.) software package is used to perform the analysis.

Around the PCFA/ACFA an air domain is considered, which extends to four times the largest dimension of the actuator in the $\mathrm{R}$ and $\mathrm{Z}$ direction, respectively. As an example, in the case of the HPN ACFA, the mesh is composed of 55000 tetrahedral elements for an axial length of $250 \mathrm{~mm}$. A reduced model of the actuator (Fig. 10) can be used by exploiting the model's periodicity. The advantage of this reduced model is the significant improvement in calculation time. Moreover, due to the constant output force characteristic of the actuator over an extended part of the stroke, the model can be further restricted to a single position which brings a significant reduction in calculation time for the optimization routine from Section VI. The evaluated dimensions and geometry for the LPN and HPN are given in Table II and Fig. 11. It needs noting that these dimensions represent by no means optimized designs and are considered solely to investigate the proof of principle. They are used to illustrate the potential of the proposed actuator configurations. The permanent magnets are assumed to be a sintered $\mathrm{NdFeB}$ with a remanence of $1.23 \mathrm{~T}$, where in the finite element analysis the standard non-linear BH-curve for mild steel, AI 1010, is used for both stationary and translating backiron.

The force-displacement characteristic of the LPN PCFA (Fig. 2) is calculated by means of the analytical model of Section II, the MEC model of Section IV and the finite element analysis, where $0 \mathrm{~mm}$ (initial position) corresponds to the stator with magnets and translator being fully aligned. Fig. 12 shows the results, for both parallel and radial magnetization patterns in the FE analysis, where a near constant force versus displacement is achieved for approximately $90 \%$ of the Zdisplacement.

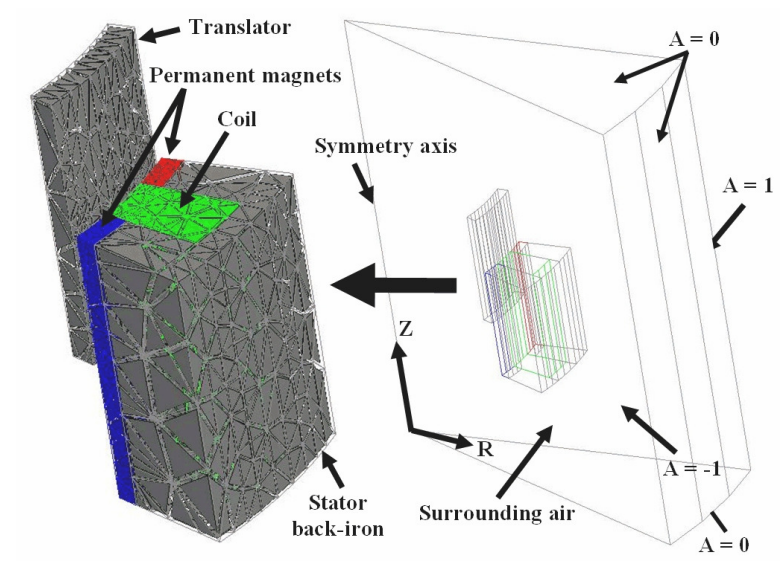

Figure 10. Reduced 3D finite element model of the CCFA with boundary conditions.

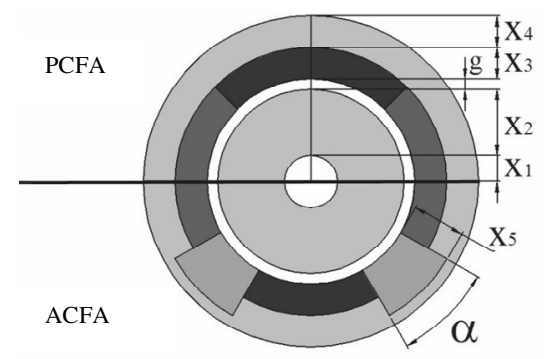

Figure 11. Schematic of the dimensions of both the PCFA (upper part) and ACFA (lower part), where $\alpha$ and $x_{5}$ determine the coil area.

TABLE II

GEOMETRICAL PARAMETERS

\begin{tabular}{cccc}
\hline \multicolumn{3}{c}{ GEOMETRICAL PARAMETERS } \\
\hline & LPN PCFA & HPN PCFA & HPN ACFA \\
\hline$x_{1}(\mathrm{~mm})$ & 3.0 & 49.0 & 49.0 \\
$x_{2}(\mathrm{~mm})$ & 8.0 & 10.0 & 10.0 \\
$g(\mathrm{~mm})$ & 1.0 & 1.0 & 1.0 \\
$x_{3}(\mathrm{~mm})$ & 3.0 & 5.0 & 5.0 \\
$x_{4}(\mathrm{~mm})$ & 5.0 & 15.0 & 15.0 \\
$x_{5}(\mathrm{~mm})$ & N/A & N/A & 15.0 \\
$\alpha\left({ }^{\circ}\right)$ & N/A & N/A & 6.0 \\
\hline
\end{tabular}

From Fig. 12 it can be concluded that a relatively large discrepancy is apparent between the analytical and the MEC models. This is due to the non-inclusion of the various leakages. Including these elements, such as in the MEC model shows that a reasonable force level estimate is achieved, albeit that still some $20 \%$ overestimate is visible of the force-displacement compared to the parallel magnetization and underestimate for the radial magnetization. For this PCFA using radial magnetized magnets clearly brings an advantage of $50 \%$ over parallel magnetization. Therefore, only the radial magnetization is used in the models of the HPN PCFA and ACFA. However, this relative increased force level of the radial magnetization will be likely diminished at an ever increasing number of poles.

The available stroke of the actuators determined by the axial length, for these examples an axial length of $50 \mathrm{~mm}$ is selected to minimize the computational requirement. 


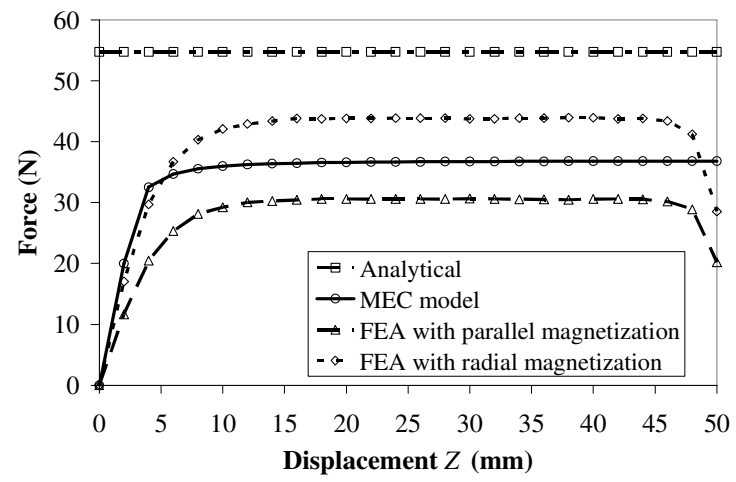

Figure 12. Force-displacement characteristic of the LPN PCFA given by analytical, MEC and FEA.

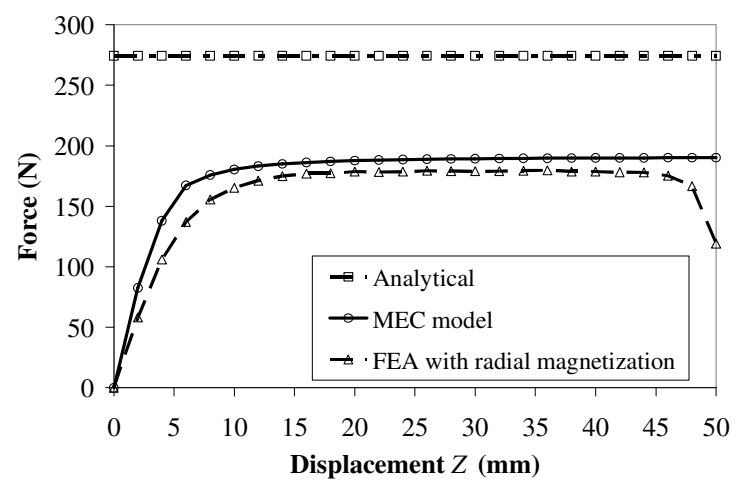

Figure 13. Force-displacement characteristic of the HPN PCFA for radial magnetization given by analytical, MEC and FEA.

However, very long strokes can be achieved and this is visible in Fig. 12 where the constant force region is about $90 \%$ of the stroke at $50 \mathrm{~mm}$.

It needs noting that an increase in axial length does not result in an increase in force level in the rise and drop-off regions of the force-displacement characteristic, hence, an increased percentage of the stroke exhibits constant force. For example, a PCFA with a length of $250 \mathrm{~mm}$ has a constant force response over a stroke of $235 \mathrm{~mm}$, respectively $94 \%$.

Further, by varying the airgap diameter of the device and the number of poles, as with the HPN PCFA shown by Fig. 3, an increased force response can be reached. The increase in the number of poles reduces the length of the mean flux tubes, flux lines, hence, the back-iron thicknesses can be reduced for the same flux density level. The achieved force-displacement characteristic, for radial magnetization and the dimension as summarized in Table II for HPN PCFA, is shown in Fig. 13.

This clearly shows that large forces, of several hundreds of newtons, can be achieved and that with the MEC model an accurate force capability of this PCFA can be established.

Clearly there would be some advantage of turning the passive into an active actuator, as shown in Fig. 4. This has the advantage that the force level can be adjusted by means of a DC-current in the meandered coil. Essentially, this offset force is determined by the amount of electrical

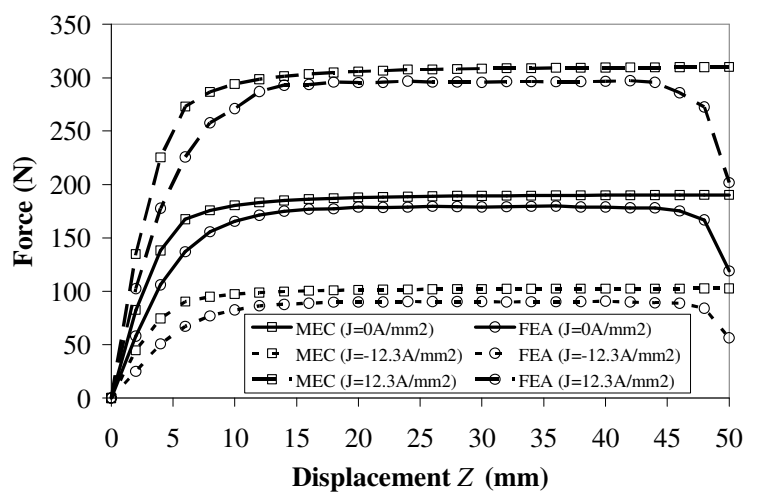

Figure 14. Force-displacement characteristic of the HPN ACFA for parallel magnetization given by MEC and FEA.

loading, hence, by the amount of copper and current density used in an actuator, viz. the number of turns and current. A principle advantage of the winding on the outside, as shown in Fig. 4, is that more cross-sectional area is available for this static stator winding, and the conduction of heat is improved. However, in this case the copper is placed in between the magnets; hence the electrical loading is limited by the thermal considerations of these magnets. The achieved force-displacement characteristics for the topology from Fig. 4, radial magnetization and the dimensions summarized in Table II for HPN ACFA, are shown in Fig. 14. For a more clear presentation and since the MEC model provides a better approximation, the analytical response is not included in Fig. 14.

The analytical equations (10) and (14) result in the passive, high active and low active force levels of respectively $274 \mathrm{~N}, 439 \mathrm{~N}$ and $147 \mathrm{~N}$. This shows that the relative differences between the models are the same, respectively: an increase of $60 \%$ for analytical, $63 \%$ for MEC and $66 \%$ for the FEA in force level for current aiding to the magnet $\mathrm{mmf}$ and a decrease of $44 \%, 44 \%$ and $50 \%$ in force level for a current opposing the magnet mmf. Further, this shows the applicability of an ACFA and the better, compared to analytical, suitability of the MEC model to estimate the amplitude of the force. The MEC model does estimate the force to within approximately $5 \%$ and captures the behavior of the passive and active force displacement characteristic even in the initial non-linear region. It needs noting that current aiding the magnet mmf provides an increased added force to the passive characteristic, which is due to the square relation between flux density and force. Effectively, for a passive force of $177 \mathrm{~N}$, a coil current, with a density of $12.3 \mathrm{~A} / \mathrm{mm}^{2}$, aiding to the magnet mmf provides $116 \mathrm{~N}$ increase in force amplitude. This would allow for the compensation of a mass variation of approximately $12 \mathrm{~kg}$.

\section{ACTUATOR OPTIMIZATION}

In order to minimize the volumetric space envelope and costs, different optimization routines can be used, where, most commonly, the design optimization is undertaken by 
means of some analytical or quasi-static numerical calculations. The disadvantage is that these methods require simplifying assumptions that can form a problem, where, most commonly, optimization results are analyzed by FEA. Furthermore, the required 3D FEA for this case is very computationally expensive and thus not the preferred method to be directly used for optimization purposes. Therefore, it can be envisaged that an optimization routine which uses the advantage of an iterative approach, involving both analytical and finite element models, will provide for a relatively fast optimization routine. In this paper an aggressive output space-mapping (AOSM) optimization technique is considered [6], since it exploits the advantages of the analysis methods of Section III, i.e. the very low computational effort of the analytical expressions and the accuracy of the FEA from Section V. Following from the space-mapping (SM) terminology, i.e. the surrogate based family of optimization techniques from which AOSM is derived, the analytical and finite element (FE) models are denoted as coarse, $\mathbf{c}(\mathbf{x})$, and fine models, $\mathbf{f}(\mathbf{x})$, respectively. It needs noting that the analytical model is chosen as a coarse model, instead of the more accurate MEC model, with the purpose of showing that SM techniques can successfully exploit very coarse models. An extra equation,

$$
T_{s}=P /\left(h_{c} S_{l}\right)+T_{a},
$$

is considered in the coarse model for calculating the stator surface temperature, based on the assumption that at steady-state the temperature is evenly distributed within the actuator volume. In this equation, $P$ is the total copper loss, $S_{l}$ is the outer stator surface, $h_{c}$ is the convection coefficient and $T_{a}$ represents the ambient temperature.

Various approximation methods are used in optimization to derive surrogate models for computationally expensive functions. The particularity of the SM techniques is that a mathematical approximation is used to correct a coarse model which inaccurately represents the physical phenomenon, where a linear response mapping is considered in AOSM. The mapping is constructed using an approximated Jacobian, $\mathbf{B}_{k}$, obtained from a rank-one Broyden update.

The core of the AOSM algorithm is structured as follows:

1. Initialize $k=1, \mathrm{~B}_{1}=\mathrm{I}$ (identity matrix), $\mathrm{y}_{1}=\mathrm{y}$ and $\varepsilon_{0}$.

2. Compute a fine model iterate:

$$
\mathbf{x}_{k}=\underset{\mathbf{x} \in X}{\arg \min }\left\|\mathbf{c}(\mathbf{x})-\mathbf{y}_{k}\right\| \text {. }
$$

3. Evaluate $\mathbf{f}\left(\mathbf{x}_{i}\right)$ and the error residuals.

4. Stop and set $\mathbf{x}^{*}=\mathbf{x}_{k}$ if an appropriate error criterion is satisfied.

5. If $k \geq 2$ update $\mathbf{B}_{k}$ :

$$
\mathbf{B}_{k}=\mathbf{B}_{k-1}+\frac{\mathbf{c}\left(\mathbf{x}_{k}\right)-\mathbf{c}\left(\mathbf{x}_{k-1}\right)-\mathbf{B}_{k-1} \mathbf{h}_{k-1}}{\mathbf{h}_{k-1}^{T} \mathbf{h}_{k-1}} \mathbf{h}_{k-1}^{T},
$$

where

$$
\mathbf{h}_{k-1}=\mathbf{f}\left(\mathbf{x}_{k}\right)-\mathbf{f}\left(\mathbf{x}_{k-1}\right)
$$

6. Set $\mathbf{y}_{k+1}=\mathbf{c}\left(\mathbf{x}_{k}\right)+\mathbf{B}_{k}\left(\mathbf{y}-\mathbf{f}\left(\mathbf{x}_{k}\right)\right), k=k+1$ and go to step 2 .

As it can be observed from the step 2 of the algorithm, the expensive fine model is replaced by the coarse one and the mapping is employed to alter, in step 6, the design specification, $\mathbf{y}_{k}$, in respect to which the coarse model is re-optimized. This approach brings the advantage that the mapping is used only once per iteration.

The HPN ACFA configuration investigated in Section $\mathrm{V}$, provides a passive constant force amplitude of approximately $200 \mathrm{~N}$, i.e. with an airgap diameter of 59.5 $\mathrm{mm}$, magnet thickness of $5 \mathrm{~mm}$, over $60 \%$ of the stroke. This actuator design is optimized in this section to achieve the $200 \mathrm{~N}$ passive response level and 50\% adjustability considering a current density of $12.5 \mathrm{~A} / \mathrm{mm}^{2}$ with a packing factor of approximately 0.6 , as summarized in Table III. The relatively high filling factor, for the meander wound coil, can be applied since this design does not include any tooth tips, as shown in Fig. 11.

The design variables $\left(x_{1, \ldots, 5}\right.$ and $\left.\alpha\right)$ are presented in Fig. 11. The optimization objective is the minimization of the translator mass and actuator outer radius for the above specified force outputs, where, giving the fixed axial length, the objective translates into a force maximization problem. The accomplished optimized long-stroke constant-force displacement characteristic of the ACFA, for the design of Fig. 4, is shown in Fig. 15, which is achieved with a translator mass of $0.66 \mathrm{~kg}$, axial length, $L_{a x}$, of $50 \mathrm{~mm}$ and 16 permanent magnet poles, where the design specifications, constraints and the various dimensions are summarized in Table III and IV.

TABLE III

DESIGN SPECIFICATIONS AND CONSTRAINTS

\begin{tabular}{lc}
\hline \hline \multicolumn{1}{c}{ Type } & Values \\
\hline $\begin{array}{l}\text { Design } \\
\text { specifications }\end{array}$ & $F_{\text {passive }}=200 \mathrm{~N}, F_{\text {active }}=300 \mathrm{~N}$, \\
& $\left(\right.$ coarse model only $\rightarrow B_{\text {stator,trans }} \leq 1.6 \mathrm{~T}, T_{\text {suf }} \leq 130^{\circ} \mathrm{C}$ ) \\
Other data & $\rho_{\text {iron }}=7650 \mathrm{~kg} / \mathrm{m}^{3}, \rho_{C u}=8900 \mathrm{~kg} / \mathrm{m}^{3}$, \\
& $\rho_{P M}=7700 \mathrm{~kg} / \mathrm{m}^{3}, B_{r}=1.23 \mathrm{~T}$ \\
$h=20 \mathrm{~W} / \mathrm{m}^{2} / \mathrm{K}$
\end{tabular}

TABLE IV

GEOMETRICAL PARAMETERS OF THE ACFA

\begin{tabular}{ccc}
\hline & Non-optimized & Optimized \\
\hline$x_{1}(\mathrm{~mm})$ & 49.0 & 56.6 \\
$x_{2}(\mathrm{~mm})$ & 10.0 & 4.7 \\
$g(\mathrm{~mm})$ & 1.0 & 1.0 \\
$x_{3}(\mathrm{~mm})$ & 5.0 & 3.9 \\
$x_{4}(\mathrm{~mm})$ & 15.0 & 18.4 \\
$x_{5}(\mathrm{~mm})$ & 15.0 & 18.2 \\
$\alpha\left({ }^{\circ}\right)$ & 6.0 & 8.7 \\
$R_{\text {outer }}(\mathrm{mm})$ & 95.0 & 85.1 \\
$L_{a x}(\mathrm{~mm})$ & 50 & 50 \\
Translator mass $(\mathrm{kg})$ & 1.29 & 0.66 \\
Total mass $(\mathrm{kg})$ & 5.13 & 3.62 \\
\hline
\end{tabular}




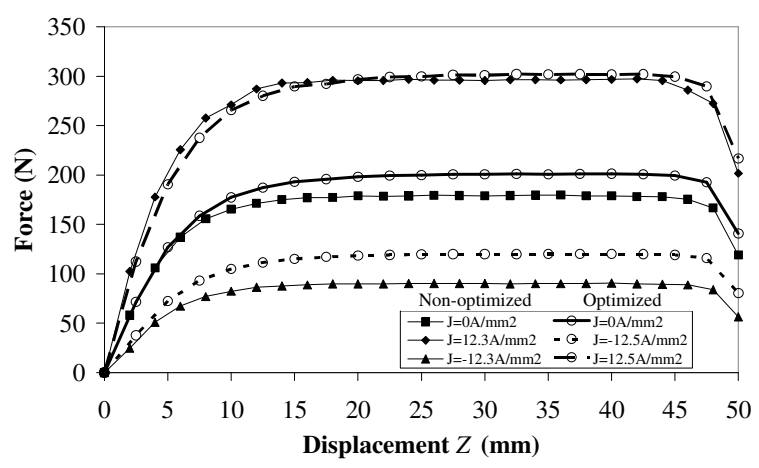

Figure 15. ACFA non-optimized and optimized forcedisplacement characteristics.

It needs noting that the design solution is obtained within ten AOSM iterations which results in the necessity of performing only ten FE evaluations. The optimization procedure of the ACFA provides for a significant improvement. For example, the outer radius is reduced from $95.0 \mathrm{~mm}$ to $85.1 \mathrm{~mm}$ and the inner radius is increased from $49.0 \mathrm{~mm}$ to $56.6 \mathrm{~mm}$.

In the above analysis the volume force density level it does not really have a meaning, since increasing the axial length does not provide for an increase in the force level, however does provide an increased stroke and constant force versus displacement. Therefore, the axial length can be reduced to have a small linear region, as shown in Fig. 16 for an axial length of $20 \mathrm{~mm}$. In this case the force density is maximized and for the optimized ACFA this provides for: $788 \mathrm{kN} / \mathrm{m}^{3}$ passively and $1182 \mathrm{kN} / \mathrm{m}^{3}$ actively, however this reduces to, using the characteristic of Fig. 15 with an axial length of $50 \mathrm{~mm}: 315 \mathrm{kN} / \mathrm{m}^{3}$ and $473 \mathrm{kN} / \mathrm{m}^{3}$, respectively. When considering the axial length of $250 \mathrm{~mm}$ this reduces further to $63 \mathrm{kN} / \mathrm{m}^{3}$ and $95 \mathrm{kN} / \mathrm{m}^{3}$.

However, since the force amplitude is not influenced by the axial length, it might be advantageous to consider the force per area, i.e. radial cross-section, instead of volume. This approach illustrates the optimization effectiveness, i.e., a force density of $15.7 \mathrm{kN} / \mathrm{m}^{2}$ is obtained for the optimized ACFA, compared with 9.6 $\mathrm{kN} / \mathrm{m}^{2}$ in the initial configuration.

\section{CONCLUSION}

Passive and active long stroke constant-force actuator topologies are investigated in this paper. This type of actuators exhibits a constant force characteristic for approximately $90 \%$ of the stroke, and, furthermore, relatively very long strokes can be achieved. Although that it is also interesting to note that implementing some compensating rings, as discussed in [7], can increase the

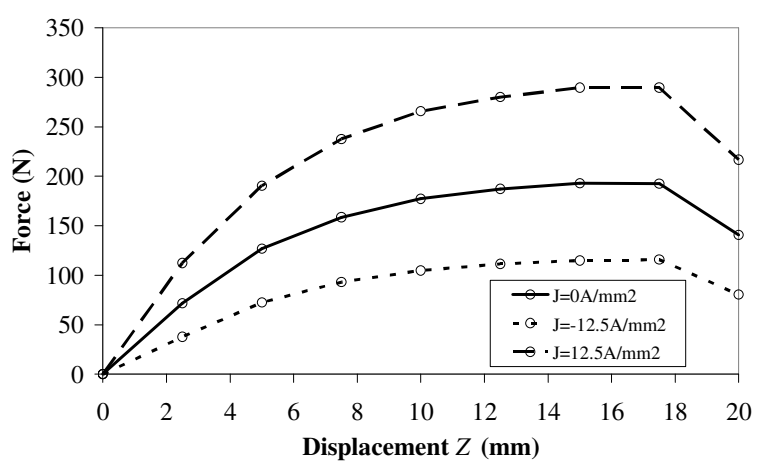

Figure 16. ACFA force-displacement characteristic for maximum force density (axial length of $20 \mathrm{~mm}$ ).

initial force to be nearly constant, hence, an almost constant force-displacement characteristic, i.e. for approximately $95 \%$ of the axial length, could be achieved even for relative short axial lengths. This paper also shows that an active version of this actuator obtained, for example, by means of implementing a meandered wound coil in between the permanent magnets, can adjust the amplitude of the force-displacement response by approximately $50 \%$, i.e. adding to or subtracting from the passive characteristic.

The paper presents the means to determine the forcedisplacement characteristics for constant-force actuators. Furthermore, an optimized ACFA design is investigated. The actuator provides a constant force-displacement output characteristic and the translator mass has been minimized for the specified force levels. The optimized ACFA is designed considering both electromagnetic and thermal aspects, for which the AOSM technique, i.e. an optimization routine based on the SM, is successfully implemented. The results show that a significant improvement of the initial design is obtained.

\section{REFERENCES}

[1] http://www.magspring.com/ MagSpring®, Haerdlistr. 15, 8967 Spreitenbach, Switzerland.

[2] B. Postma, T. Vinay, T. Kangsanant, A. Harvey, "Electromagnetic Flat-Faced Robot Gripper for Handling Multiple Industrial Transformer Core Lamination Plates", IEEE Transactions on Magnetics, Vol. 34, No. 3, pp. 700-707, 1998.

[3] B.P. Lequesne, "Finite-Element Analysis of a Constant-Force Solenoid for Fluid Flow Control", IEEE Transactions on Magnetics, Vol. 34, No. 3, pp. 574-581, 1988.

[4] H. C. Roters. Electromagnetic devices. New York: Wiley, 1941

[5] V. Ostovic. Dynamics of saturated electric machines. Springer, 1989

[6] L. Encica, J.J.H. Paulides, E.A. Lomonova, A.J.A. Vandenput, "Aggressive output space mapping optimization for electromagnetic actuators", IEEE Transactions on Magnetics, to be published.

[7] R.E. Clark, G.W. Jewell, P. Stewart and D. Howe: "Tailoring force-displacement in medium-stroke linear variable reluctance actuators", IEEE Trans. On Magnetics, Vol. 38, No. 5, 2002. 